\title{
CHIMIE ORGANIQUE
}

\author{
Stéréochimie, \\ entités réactives \\ et réactions
}

René MILCENT

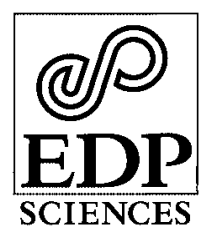

17, avenue du Hoggar

Parc d'Activité de Courtabœuf, BP 112 91944 Les Ulis Cedex A, France 


\section{Du même auteur :}

\section{Chimie organique hétérocyclique, EDP Sciences, 2003}

\section{Imprimé en Espagne}

ISBN : 978-2-86883-875-9

Tous droits de traduction, d'adaptation et de reproduction par tous procédés, réservés pour tous pays. La loi du 11 mars 1957 n'autorisant, aux termes des alinéas 2 et 3 de l'article 41, d'une part, que les « copies ou reproductions strictement réservées à l'usage privé du copiste et non destinées à une utilisation collective », et d'autre part, que les analyses et les courtes citations dans un but d'exemple et d'illustration, « toute représentation intégrale, ou partielle, faite sans le consentement de l'auteur ou de ses ayants droit ou ayants cause est illicite » (alinéa $1^{\text {er }}$ de l'article 40). Cette représentation ou reproduction, par quelque procédé que ce soit, constituerait donc une contrefaçon sanctionnée par les articles 425 et suivants du code pénal. 